\title{
Effect of short-chain carbohydrates on human intestinal bifidobacteria and Escherichia coli in vitro
}

\author{
R. SHARP, S. FISHBAIN* and G. T. MACFARLANE $\dagger$
}

School of Applied Sciences, South Bank University, 103 Borough Road, London SE1 OAA, *Department of Civil Engineering, Technological Institute, Northwestern University, Evanston IL 60201, USA and †MRC Microbiology and Gut Biology Group, Level 6, Ninewells Hospital and Medical School, Dundee DD1 9SY

\begin{abstract}
Plate counts and small subunit (SSU) rRNA abundance were used to study the effects of fructo-oligosaccharides (FOS), fructose, or galacto-oligosaccharides (GOS) on bifidobacterial populations in human faecal microbiotas. The bacteria were grown in pHcontrolled anaerobic fermentation vessels. Untreated cultures and fructose-amended fermenters were used as controls. Bifidobacterium longum, B. adolescentis and $B$. angulatum comprised the dominant bifidobacterial populations throughout the experiment. No major differences were found in the four treatments, in terms of viable counts of the organisms or of total populations of bifidobacteria at any time point. However, large differences were observed with respect to the abundance of bifidobacterial SSU rRNA between the treatments. Greatest bifidobacterial SSU rRNA abundance was seen in FOS cultures, with the lowest in the untreated control fermentation. GOS and fructose also increased bifidobacterial SSU rRNA. Cultures supplemented with FOS and GOS were also associated with lower colony counts and SSU rRNA abundance for Escherichia coli, compared with fructose-supplemented and control fermenters. At the 24-h time point, the untreated control contained $19.8 \mu \mathrm{g}$ of enterobacterial SSU rRNA/ml of culture fluid, compared with $11.4 \mu \mathrm{g} / \mathrm{ml}$ for the fructose fermentation, and 2.6 and $0.5 \mu \mathrm{g} / \mathrm{ml}$ for the FOS and GOS culture vessels, respectively.
\end{abstract}

\section{Introduction}

Species belonging to the genus Bifidobacterium are often amongst the most prevalent bacteria in the human large intestine, after the bacteroides and eubacteria [1]. Bifidobacteria are obligately saccharolytic anaerobes that play an important role in the breakdown of complex carbohydrates that are resistant to hydrolysis by human digestive enzymes [2, 3]. They can comprise up to $25 \%$ of the total cultivable gut microflora [4], the most common isolates from adults being $B$. adolescentis and $B$. longum, with $B$. infantis more characteristically being found in infants. Bifidobacteria are currently attracting considerable scientific interest due to increasing recognition of their health promoting potential [5]. These organisms have variously been implicated in competition with pathogenic and putrefactive bacteria for nutrients and attachment sites in the

Received 17 Jan. 2000; revised version received 19 June 2000; accepted 20 June 2000.

Corresponding author: Dr R. Sharp (e-mail: sharp@sbu. ac.uk). gut [6], immune stimulation [7], production of organic acids that acidify the large intestine and the formation of substances that inhibit the growth of human pathogens $[8,9]$.

Recent research has focused to large degree on the abilities of bifidobacteria to break down non-digestible oligosaccharides (NDO) such as fructo-oligosaccharides (FOS), and the effects of these substrates on the numbers and activities of bifidobacteria in the large bowel $[10,11]$. FOS are a group of naturally occurring oligosaccharides, comprising several $\beta(1-2)$ - or $\beta(1-6)$ linked fructosyl units, usually attached to a terminal glucose residue. Like many complex plant carbohydrates, they cannot be hydrolysed by human digestive enzymes but are broken down by glycosidases formed by bacteria growing in the large intestine. Some FOS have been shown to stimulate bifidobacteria in vivo, as demonstrated in feeding studies with human volunteers [12]. Other galactose-containing NDO such as the galacto-oligosaccharides (GOS) also stimulate bifidobacteria, although this is not a universal property of all NDO $[13,14]$. 
Quantitative analysis of microbial communities by hybridisations with oligonucleotide probes complementary to the small subunit (SSU) ribosomal RNA (rRNA) of individual and phylogenetically coherent groups of organisms is an increasingly well characterised technique $[15,16]$ that is becoming an effective tool to study the microbial populations of the large intestine [17-20]. The combined use of culture-based techniques and rRNA probe methodology offers a strong alternative approach to viable counting procedures in studies on the effect of substrate availability on microbial ecology.

This investigation was designed to address two questions concerning the relationship between bifidobacteria and NDO. Firstly, the studies were aimed at comparing the stimulatory effects of fructose and different NDO on populations of bifidobacteria. The other objective was to determine whether stimulation of bifidobacterial growth resulted in inhibition of enterobacteria. To address this question, the effects of different fermentable carbon sources were tested in $\mathrm{pH}$-controlled batch cultures inoculated with human faeces by use of a combination of culture-based techniques and rRNA-targeted oligonucleotide probes.

\section{Materials and methods}

\section{Batch culture fermentation systems}

Intestinal bacterial suspensions $(25 \% \quad \mathrm{w} / \mathrm{v})$ were prepared from fresh faeces homogenised with $100 \mathrm{mM}$ anaerobic sodium phosphate buffer $(\mathrm{pH}$ 7.0). The homogenates were filtered through a $100-\mu \mathrm{m}$ metal sieve to remove large food particles. The filtrates $(50 \mathrm{ml})$ were inoculated into glass fermentation vessels ( $275 \mathrm{ml}$ working volume) containing $200 \mathrm{ml}$ of sterile culture medium consisting of the following $(\mathrm{g} / \mathrm{L})$ : Lintners starch (BDH), 4.0; xylan (oatspelt), 1.0; pectin (citrus), 2.0; guar gum, 1.0; porcine gastric mucin (Sigma type III), 4.0; arabinogalactan (larch wood), 4.0; chondroitin sulphate, 0.5 ; bacteriological peptone, 5.0; Tryptone, 4.0; yeast extract, 4.0; casein (BDH), $2.0 ; \mathrm{NaCl}, 4.5 ; \mathrm{K}_{2} \mathrm{HPO}_{4}, 0.4 ; \mathrm{MgCl}_{2} .6 \mathrm{H}_{2} \mathrm{O}, 0.15$; $\mathrm{NH}_{4} \mathrm{Cl}, 0.25$; cysteine, 0.50 ; vitamin $\mathrm{B}_{12}, 0.005$; haemin, 0.01; menadione, 0.005; Tween 80, 1.0. In addition, $1 \mathrm{ml}$ of a trace mineral solution [21] was added/L of culture medium. Carbohydrate supplements $(10 \mathrm{~g} / \mathrm{L})$ were added as sterile solutions to the basal culture medium as follows: treatment A (FOS, Raftiline $\mathrm{LS}$ ), treatment $\mathrm{B}$ (fructose), treatment $\mathrm{C}$ (control, no supplement), treatment D (GOS). The temperature and $\mathrm{pH}$ of the fermentation vessels were controlled as described previously [22]. The vessels were stirred magnetically and maintained under an atmosphere of $\mathrm{O}_{2}$-free $\mathrm{CO}_{2}$.

\section{Culture media}

Samples $(1 \mathrm{ml})$ were taken from the fermentation vessels and serially diluted in half-strength WilkinsChalgren broth. Wilkins-Chalgren agar (WCA) was used for enumeration of total anaerobes, enterobacterial populations were grown on MacConkey agar no. 2 and bifidobacteria were grown on Beerens medium [23], Rogosa agar [24] and Wilkins-Chalgren agar. Triplicate plates were inoculated with $100-\mu 1$ samples from each dilution tube and incubated for 3 days at $37^{\circ} \mathrm{C}$, in an anaerobic chamber $\left(\mathrm{H}_{2} 10 \%, \mathrm{CO}_{2} 10 \%, \mathrm{~N}_{2} 80 \%\right)$. The study did not aim to differentiate $B$. longum, $B$. adolescentis and $B$. angulatum by means of selective media. In our experience, several species of bifidobacteria are readily cultured on Rogosa, Beerens and Wilkins-Chalgren agar; however, the identity of each of the colony types isolated on each agar was differentiated by cell-wall fatty acid analysis (as described below), therefore any potential overlap was accounted for in this way.

\section{Bacterial identification by analysis of cellular fatty acid profiles}

Fatty acid methyl esters (FAME) were extracted from cultured biomass (c. $40 \mathrm{mg}$ wet weight) obtained from $20 \mathrm{ml}$ of an overnight culture grown in peptone yeast broth [25] by saponification, methylation and extraction as described previously [26]. The FAME were separated by a model 6890A microbial identification system (Microbial ID, Newark, DE, USA) which consisted of a Hewlett-Packard model 6890 gas chromatograph fitted with a 5\% phenyl-methyl silicone capillary column $(0.2 \mathrm{~mm} \times 25 \mathrm{~m})$, a flame ionisation detector, a HewlettPackard model 7637A automatic sampler and a HewlettPackard Vectra XM computer. The gas chromatographic parameters were as follows: carrier gas, ultra-high purity hydrogen; column head pressure, $60 \mathrm{kpa}$; injection port temperature, $300^{\circ} \mathrm{C}$. Peaks were automatically integrated and fatty acid names and percentages were calculated. Numerical analyses and predictions of bacterial identification were done with standard MIS Library Generation Software (Microbial ID).

\section{rRNA extraction and oligonucleotide probe hybridisation}

Samples $(500 \mathrm{mg})$ of chemostat fluid in 2.2-ml screwcap tubes were initially subjected to direct phenol extraction with mechanical disruption (Mini-Bead beater, Biospec Products, Bartlesville, OK, USA) with $300 \mathrm{mg}$ of zirconium beads [15]. All glassware was baked at $300^{\circ} \mathrm{C}$ overnight and solutions were prepared with diethyl pyrocarbonate-treated double-distilled water. Mechanical disruption was followed by another extraction with Tris- $\mathrm{HCl}$ buffer (100 mM, pH 5.1) saturated phenol, and two sequential phenol:chloroform: isoamylalcohol (24:24:1, pH 5.1) and chloroform:isoamylalcohol extractions. Total rRNA was precipitated at $-20^{\circ} \mathrm{C}$ for $3 \mathrm{~h}$ with ammonium acetate $(1 \mathrm{M}$ final concentration). After two washes in ethanol $80 \%$, pellets were resuspended in $50 \mu \mathrm{l}$ of double-distilled 
water. The quality of extracted rRNA was evaluated by polyacrylamide gel electrophoresis (Mighty Small II Slab Gel Electrophoresis Unit, Hoefer Scientific Instruments, San Francisco, CA, USA) and the concentration of nucleic acid was determined spectrophotometrically $(1 \mathrm{mg}$ of $\mathrm{RNA} / \mathrm{ml}=25 \mathrm{OD}$ units at $260 \mathrm{~nm})$.

\section{Probes and labelling}

Table 1 lists the oligonucleotide probes used in this study and the source of the sequence. Probe groups targeted were total bacterial rRNA, a Bifidobacterium genus probe, and a probe for the enterobacterial group. Synthetic HPLC-purified oligonucleotide probes were $5^{\prime}$ end-labelled with ${ }^{32} \mathrm{P}$ by means of polynucleotide kinase (Gibco BRL) and $\left[\gamma_{-}{ }^{32} \mathrm{P}\right]$ ATP (ICN, The Netherlands) with a specific activity of $>5000 \mathrm{Ci} /$ mmol and a concentration of $10 \mathrm{mCi} / \mathrm{ml}$, as described previously [16].

\section{Hybridisation of nucleic acids}

Nucleic acids were denatured and diluted to $1.5 \mathrm{ng} / \mu \mathrm{l}$ [16]. Samples were applied in triplicate, $50 \mu \mathrm{l} / \mathrm{slot}$, to Magna Charge membranes (Micron Separation, Westboro, MA, USA) with a slot blot device (Minifold II, Schleicher \& Schuell, Keene, NH, USA) under slight vacuum to pull the entire sample through the membrane in $<2 \mathrm{~min}$. Membranes were air-dried and then baked for $2 \mathrm{~h}$ at $80^{\circ} \mathrm{C}$. DNA oligonucleotide probes, complementary to SSU rRNA, were used to determine the general microbial community structure of the samples. The DNA oligonucleotide probes were synthesised, purified and $5^{\prime}$ end-labelled with ${ }^{32} \mathrm{P}$ [30]. Baked membranes were pre-wetted in hybridisation buffer $-0.9 \mathrm{M} \mathrm{NaCl}, 50 \mathrm{mM}$ sodium phosphate $(\mathrm{pH}$ 7.0), $5 \mathrm{~mm}$ EDTA, 10× Denhardt solution [30], SDS $0.5 \%$, poly (A) $0.05 \mathrm{mg} / \mathrm{ml}$ - and placed in hybridisation tubes (Robbins Scientific, Sunnyvale, CA, USA). Membranes were incubated with $c .10 \mathrm{ml}$ of hybridisation buffer for $2 \mathrm{~h}$ at $40^{\circ} \mathrm{C}$ in a rotating incubator (Robbins Scientific). The first hybridisation buffer was discarded and labelled probe was added by inclusion in a volume of hybridisation buffer equal to that used in the initial incubation. The incubation was then continued at $40^{\circ} \mathrm{C}$ for $16-20 \mathrm{~h}$, then the membranes were washed in the hybridisation tubes with $100 \mathrm{ml}$ of SDS $1 \%-1 \times \operatorname{SSC}(0.15 \mathrm{M} \mathrm{NaCl}$ plus $0.015 \mathrm{M}$ sodium citrate, $\mathrm{pH} 1.0$ ) for $2 \mathrm{~h}$ at $40^{\circ} \mathrm{C}$, replacing the wash solution after $1 \mathrm{~h}$. Membranes were then removed from the hybridisation tubes and washed twice for $15 \mathrm{~min}$ in
$300 \mathrm{ml}$ of SDS $1 \%-1 \times \mathrm{SSC}$ at the experimentally determined dissociation temperatures for individual probes.

\section{Imaging and quantification of hybridisation signal}

Hybridisation signal on air-dried membranes was quantified by an Instant Imager (Canberra Packard, Pangbourne, Berks). The time of exposure varied depending on the intensity of the ${ }^{32} \mathrm{P}$ signal. The ${ }^{32} \mathrm{P}$ signal was quantified and integrated with an ImageQuant software package (Molecular Dynamics, Sunnyvale, CA, USA). The abundance of specific groups of organisms is presented as either total quantities of rRNA relating to each probe group, or as percentages of total bacterial SSU rRNA in the sample. Standard curves were calculated from reference RNA by linear regression. RNAs from $B$. longum (bacterial and Bifidobacterium genus probe) and Escherichia coli (enterobacterial group probe) were used.

\section{Chemicals}

Formulated bacteriological culture media were purchased from Oxoid. NDO were obtained from the following suppliers: Raftiline LS (Orafti, Tienen, Belgium), GOS (Yakult, Japan). Unless stated otherwise, all chemicals were obtained from Sigma.

\section{Results}

\section{Bacteriology}

Bacterial identification was based on cell-wall fattyacid analysis under standard conditions [26]. The focus of the bacteriology was populations of bifidobacteria isolated from Beerens agar, WCA and Rogosa agar plates. The total anaerobe count was determined on WCA and colonies on these plates represented a diverse range of genera including Bacteroides, Eubacterium, Clostridium, E. coli, Streptococci and Enterococcus; however, the study focused on populations of E. coli in these mixtures.

\section{Effect of NDO on faecal bacterial populations}

Total anaerobe counts and total bacterial SSU ribosomal abundance were used to assess the effects of different treatments on faecal bacterial populations. Values for total anaerobe counts and ribosomal abundance at $24 \mathrm{~h}$ are shown in Tables 2 and 3. No major differences in total anaerobe counts were

Table 1. 16S rRNA-targeted oligonucleotide probes used for analysis of bacterial populations

\begin{tabular}{llll}
\hline Probe & Sequence 5'-3' & Name* & Td \\
\hline Eubacterial & GCTGCCTCCCGTAGGAGT & S-D-bact-0338-1-A-18 & 48 \\
Bifidobacterium (genus) & CATCCGGCATTACCACCC & S-G-Bif-164-a-A-18 & 27 \\
Enterobacterial & CTTTTGCA(A/G)CCCACT & Not applicable & 28 \\
\hline
\end{tabular}

*Oligonucleotide probe database nomenclature [29]. 
Table 2. Effect of non-digestible oligosaccharides on culture counts after incubation for $24 \mathrm{~h}$

\begin{tabular}{lcccc}
\hline & \multicolumn{4}{c}{ Mean $\log _{10}$ viable counts with } \\
\cline { 2 - 5 } Species & FOS $10 \mathrm{~g} / \mathrm{L}$ & fructose $10 \mathrm{~g} / \mathrm{L}$ & no treatment & GOS $10 \mathrm{~g} / \mathrm{L}$ \\
\hline Total bifidobacteria & 7.56 & 7.55 & 7.31 & 7.65 \\
B. longum & 6.94 & 6.29 & 6.99 & 6.36 \\
B. adolescentis & 7.45 & 7.18 & 7.04 & 6.22 \\
B. angulatum & 7.17 & 6.96 & 6.83 & 7.28 \\
Total anaerobes & 8.62 & 8.59 & 8.38 & 8.64 \\
E. coli & 5.52 & 6.07 & 6.50 & 5.23 \\
\hline
\end{tabular}

Results are mean $\log _{10}$ viable counts $/ \mathrm{ml}, \mathrm{n}=2$.

Table 3. Effect of non-digestible oligosaccharides and fructose on SSU rRNA abundance after incubation for $24 \mathrm{~h}$

\begin{tabular}{lcccc}
\hline & \multicolumn{4}{c}{ Mean SSU rRNA abundance with } \\
\cline { 2 - 5 } Probe & FOS $10 \mathrm{~g} / \mathrm{L}$ & fructose $10 \mathrm{~g} / \mathrm{L}$ & no treatment & GOS $10 \mathrm{~g} / \mathrm{L}$ \\
\hline Eubacterial & 603 & 377 & 319 & 286 \\
Bifidobacterium (genus) & 68.5 & 26.7 & 16.5 & 32.8 \\
Enterobacterial & 2.6 & 11.4 & 19.8 & 0.5 \\
Percentage of total & & & 5.2 & 11.5 \\
$\quad$ Bifidobacterium (genus) & 11.4 & 7.1 & 6.2 & 0.2 \\
Enterobacterial & 0.4 & 3.0 & & \\
\hline
\end{tabular}

Values are $\mu \mathrm{g}$ SSU $\mathrm{rRNA} / \mathrm{ml}$ of culture medium.

apparent at this time point, with the exception that counts for total anaerobes were lower in the untreated control. At $24 \mathrm{~h}$, total SSU rRNA abundance was greatest with FOS. Figs. 1 and 2 show the effect of the substrates at each time point on counts of total anaerobes, and bacterial SSU rRNA abundance, respectively. Fig. 1 shows that this trend can also clearly be seen at $6 \mathrm{~h}$ and $12 \mathrm{~h}$. Bacterial rRNA abundance was highest in the fructose vessel in the early stages of the fermentation.

\section{Effect of NDO on bifidobacteria}

Plate counts and SSU rRNA abundance were used to measure the effects of NDO and fructose on bifidobacteria. Results from the plate counts at $24 \mathrm{~h}$ are

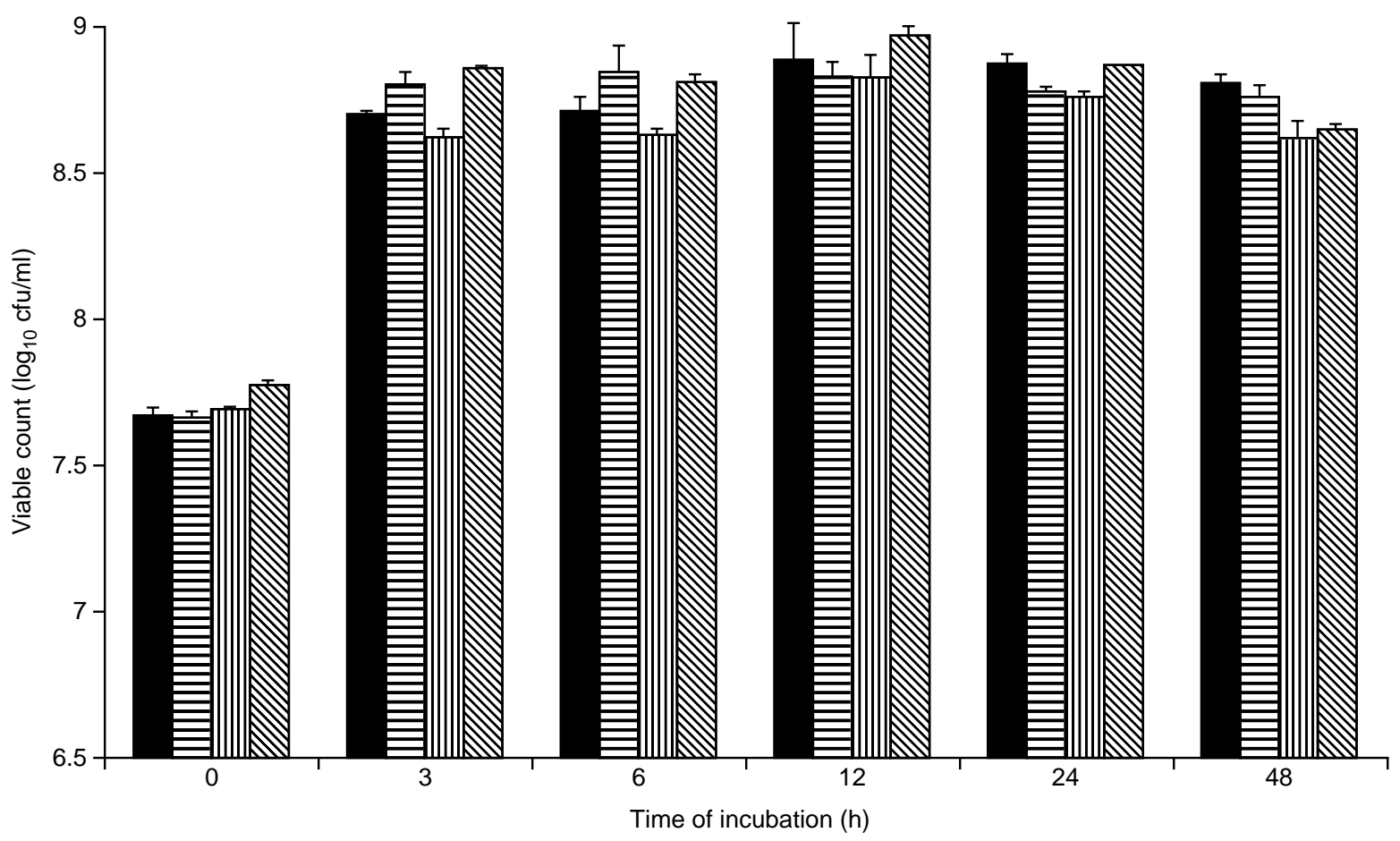

Fig. 1. Effect of different carbohydrate substrates on total anaerobe counts in the fermentation vessels: $\mathbf{\square}, \mathrm{FOS} 10 \mathrm{~g} / \mathrm{L}$; 目, fructose $10 \mathrm{~g} / \mathrm{L} ; \mathbb{W}$, no treatment; $\mathbb{Q}$, GOS $10 \mathrm{~g} / \mathrm{L}$. Results show mean $\log _{10}$ viable counts $/ \mathrm{ml}$ and $\mathrm{SD}, \mathrm{n}=2$. 


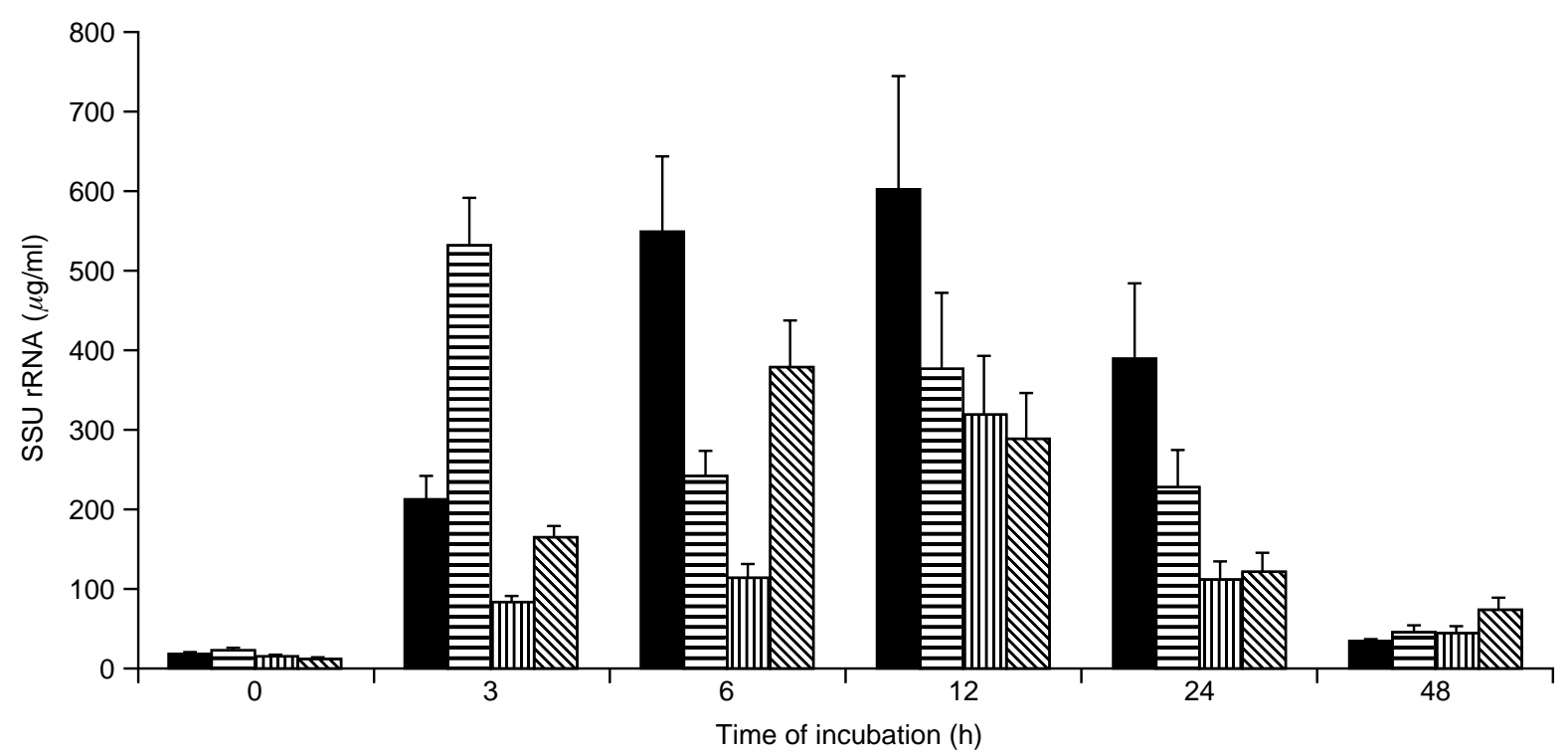

Fig. 2. Effect of supplementation with different carbohydrate substrates on abundance of bacterial SSU rRNA

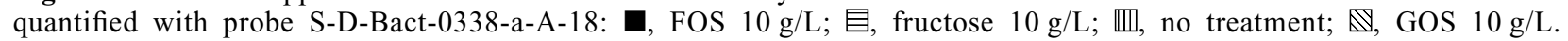
Each value represents the mean of triplicate hybridisations and SD.

shown in Table 2. B. longum, $B$ adolescentis and $B$. angulatum comprised the dominant bifidobacterial populations throughout the experiment. No major differences were observed in terms of viable counts of individual species or total populations of bifidobacteria. The control fermenters had the lowest bifidobacterial counts. More detailed analysis of the effects of each treatment at each time point $(0,3,612,24,48 \mathrm{~h})$ for total bifidobacteria, B. longum, B. adolescentis and $B$. angulatum is shown in Fig. $3 \mathrm{a}, \mathrm{b}, \mathrm{c}$ and $\mathrm{d}$, respectively. The results demonstrate that at $48 \mathrm{~h}$, higher numbers of $B$. adolescentis and B. angulatum were present in cultures supplemented with both NDO. The abundance of bifidobacterial SSU rRNA for each treatment at $24 \mathrm{~h}$ is shown in Table 3, and for all time points in Fig. 4. Unlike the plate counts, there were marked differences between treatments. The largest bifidobacterial SSU rRNA abundance occurred with FOS, and the lowest in untreated control. Results with GOS and fructose fermenters were similar to each other. When data for bifidobacterial SSU rRNA abundance were expressed as a proportion of total bacterial SSU rRNA, the same trend was observed (Table 3), with the two NDO-supplemented cultures having the greatest percentage of bifidobacterial SSU rRNA $(11.4 \%$ and $11.5 \%$ for FOS and GOS, respectively).

\section{Effect of NDO on E. coli}

Results for E. coli at $24 \mathrm{~h}$ are shown in Table 2. Counts of $E$. coli were highest in the unsupplemented control and fructose cultures. Fermentation vessels containing the two NDO had the lowest E. coli populations. This was more apparent in measurements of enterobacterial SSU rRNA evaluated with the probe for enterobacteria. SSU rRNA determined with this probe for the enterobacterial group of bacteria includes $E$. coli rRNA. Values for counts of E. coli and abundance of SSU rRNA are shown in Figs. 5 and 6 respectively. The untreated batch culture contained $19.8 \mu \mathrm{g}$ of enterobacterial SSU $\mathrm{rRNA} / \mathrm{ml}$ of culture fluid, compared with $11.4 \mu \mathrm{g} / \mathrm{ml}$ for the fructose-supplemented batch culture and 2.6 and $0.5 \mu \mathrm{g} / \mathrm{ml}$ for the FOS and GOS fermenters, respectively (Table 3 ). When the results for enterobacterial SSU rRNA abundance were expressed as a proportion of total bacterial SSU rRNA (Table 3), the same trend was observed, with the untreated control having the greatest percentage of enterobacterial SSU rRNA.

\section{Discussion}

The effect of supplementation with FOS, GOS and fructose on human faecal bifidobacteria grown in batch cultures has been investigated with culture-based methodologies and SSU rRNA-targeted oligonucleotide DNA probes. Throughout the experiment, emphasis was given to the response of bifidobacterial populations because of increasing reports in the literature concerning the stimulatory effect of some NDO on bifidobacteria $[8,12]$. The study also investigated the effects of NDO stimulation of bifidobacteria on E. coli in faecal material.

B. longum, B. adolescentis and B. angulatum comprised the dominant bifidobacterial populations throughout the experiment. These organisms were identified by bacterial FAME analysis by the MIDI system. Identification according to this method is based upon comparison with a library of FAME profiles for bacteria grown in identical conditions. The technique is used routinely in this laboratory for the identification of 


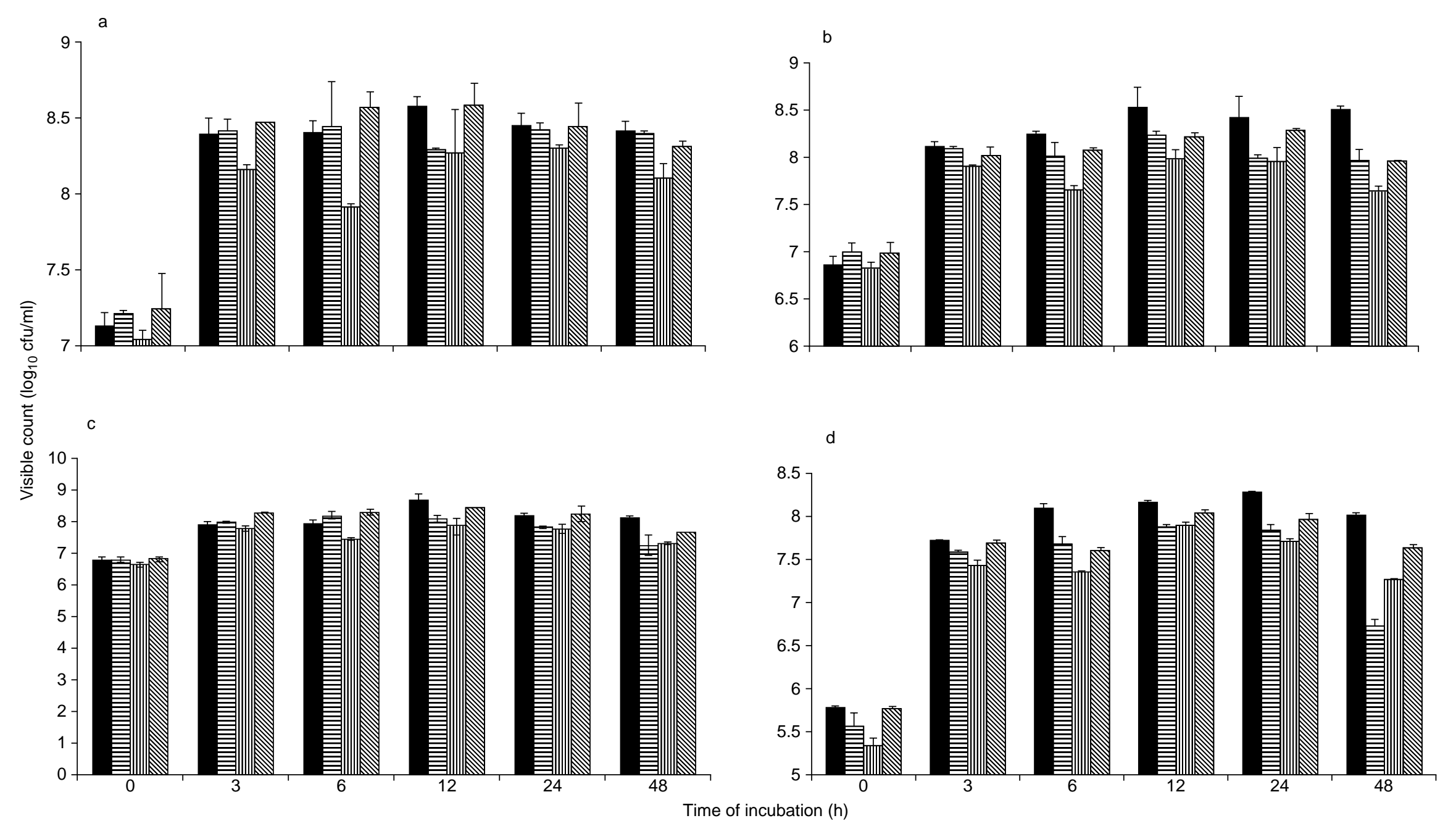

Fig. 3. Effect of different carbohydrate substrates on bifidobacteria counts. (a) Total bifidobacteria, (b)
$10 \mathrm{~g} / \mathrm{L} ; \mathbb{W}$, no treatment; $\mathbb{Q}$, GOS $10 \mathrm{~g} / \mathrm{L}$. Results show mean $\log _{10}$ viable counts/ml and $\mathrm{SD}, \mathrm{n}=2$. 


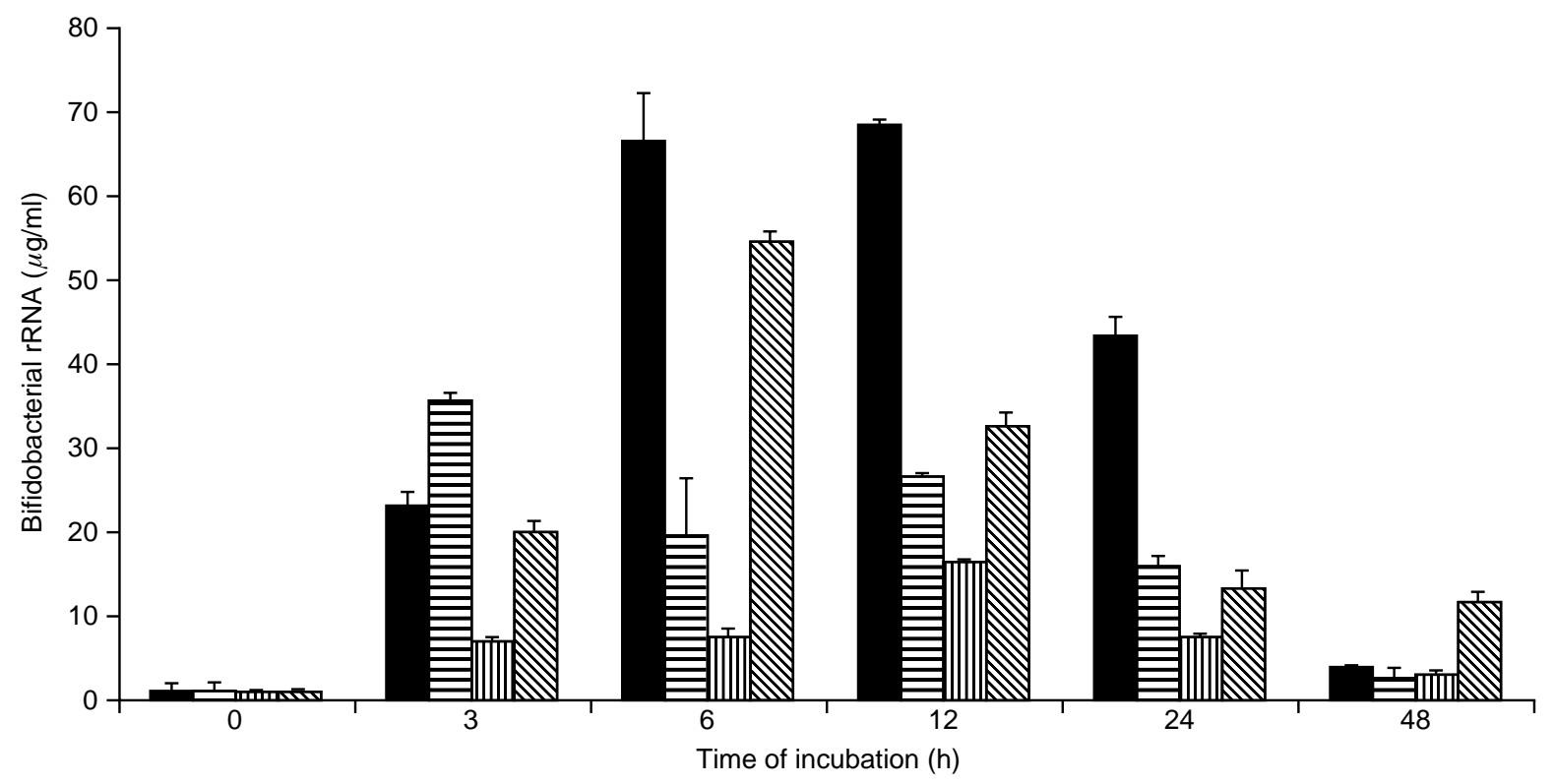

Fig. 4. Effect of supplementation with different carbohydrate substrates on abundance of bifidobacterial SSU rRNA quantified with probe S-G-Bif-164-a-A-18: $\mathbf{\square}$, FOS $10 \mathrm{~g} / \mathrm{L}$; 目, fructose $10 \mathrm{~g} / \mathrm{L} ; \mathbb{U}$, no treatment; $\mathbb{Q}$, GOS $10 \mathrm{~g} / \mathrm{L}$. Each value represents the mean of triplicate hybridisations and SD.

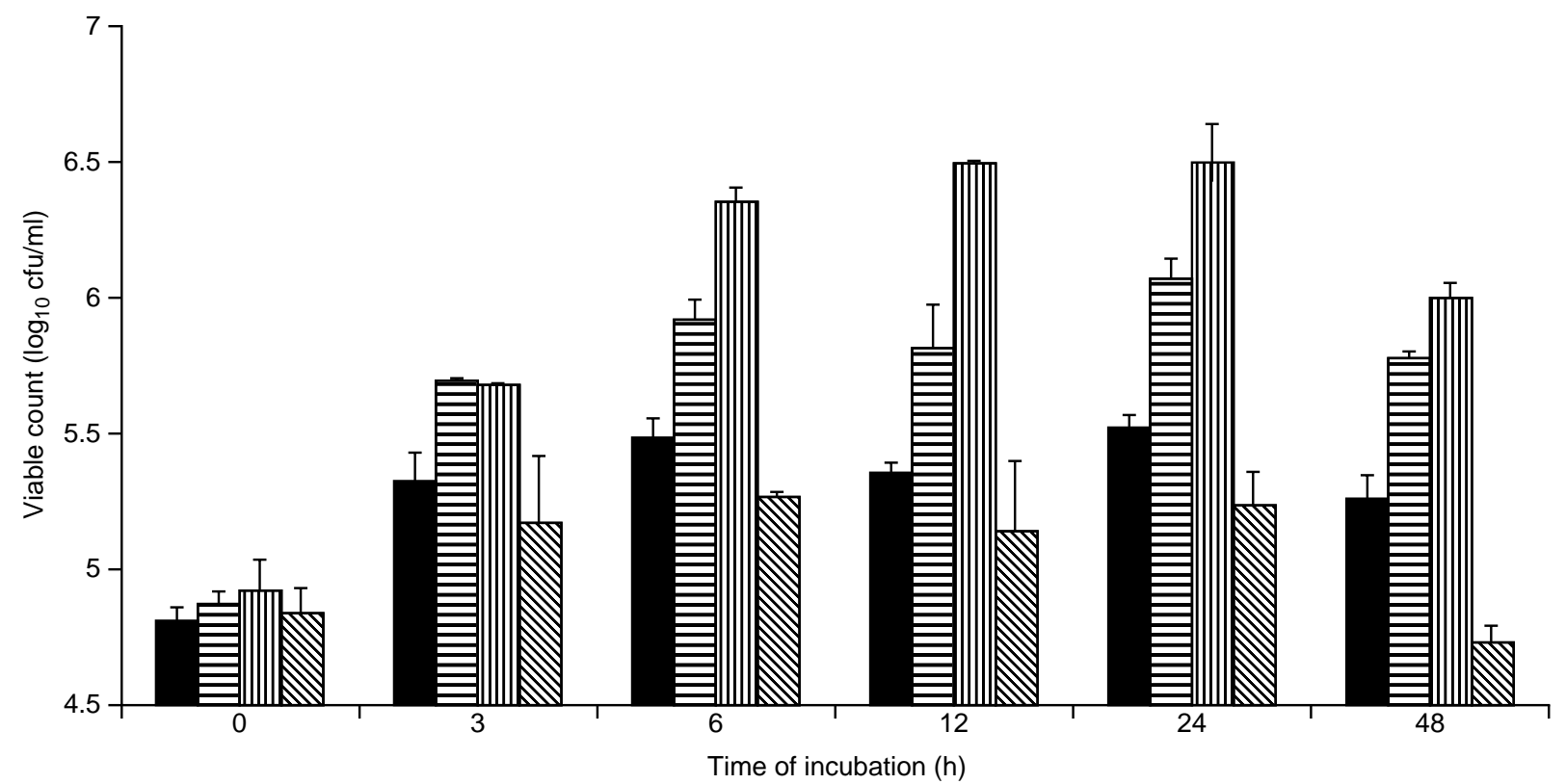

Fig. 5. Effect of carbohydrate on E. coli counts: $\mathbf{\square}$, FOS $10 \mathrm{~g} / \mathrm{L}$; 目, fructose $10 \mathrm{~g} / \mathrm{L}$; 四, no treatment; $\mathbb{\nabla}$, GOS $10 \mathrm{~g} / \mathrm{L}$. Results show mean $\log _{10}$ viable counts/ml and $\mathrm{SD}, \mathrm{n}=2$.

bacteria at the genus and often the species level $[31,32]$.

The genus-specific bifidobacterial probe used in this study was originally developed for fluorescent-labelling investigations in faeces [28]. However, it has subsequently been used for dot-blot hybridisation protocols with rRNA extracted from human faeces [19, 20, 33]. The abundance of rRNA corresponding to this genus was surprisingly low in fermenters inoculated with faeces compared with an average proportion of $37 \%$ determined by plate counts to enumerate bifidobacteria.
However, there are now a number of studies confirming that bifidobacteria can be overestimated by culturedependent methods. The evidence suggests that faecal bifidobacteria are highly culturable, much more so than many other groups of anaerobes in gut contents. In previous studies [28,34], fluorescent probe-based estimations of bifidobacteria have equalled culture counts, whereas total anaerobe numbers have been underestimated by a factor of 10 .

For the enumeration of bifidobacteria in this study, traditional methods of bacterial enumeration based on 


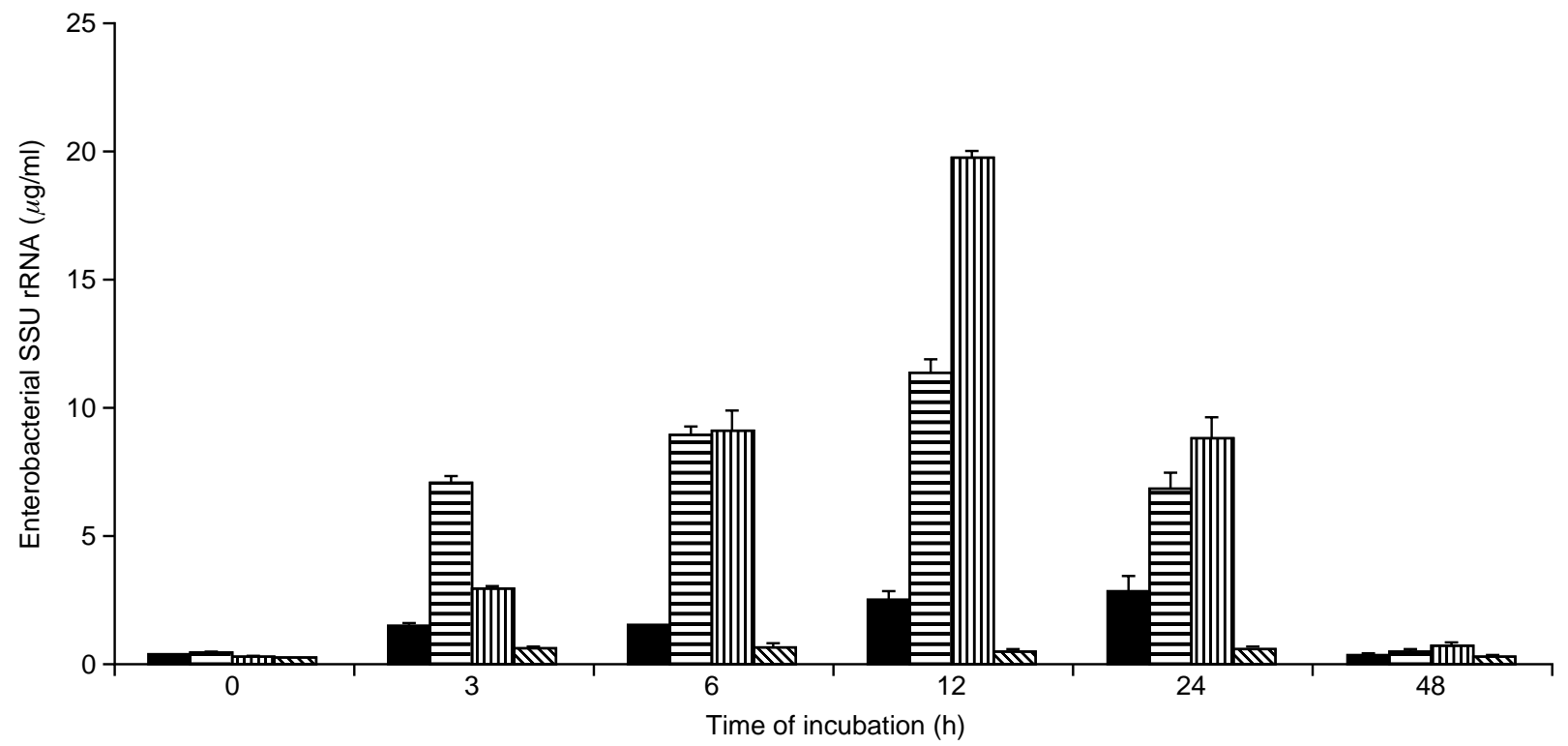

Fig. 6. Effect of carbohydrate substrates on enterobacterial SSU rRNA: $\mathbf{0}$, FOS $10 \mathrm{~g} / \mathrm{L}$; 目, fructose $10 \mathrm{~g} / \mathrm{L}$; 血, no treatment; $\mathbb{Q}$, GOS $10 \mathrm{~g} / \mathrm{L}$. Each value shows the mean of triplicate hybridisations and SD.

plate counts contrasted with results obtained with SSU rRNA targeted oligonucleotide probes. The latter method revealed marked differences between the treatments, with the largest bifidobacterial SSU rRNA abundance occurring in the FOS-supplemented cultures and the lowest in the untreated control. Similar phenomena were observed in continuous culture enrichments of faecal bifidobacteria and lactobacilli, with FOS supplements. When bacteria from the continuous culture were enumerated by traditional methods, bifidobacteria appeared to outnumber lactobacilli over the whole period of the experiment. However, according to the probe data, bifidobacteria were not detectable 3 days into a 21-day protocol [11].

Although the results obtained with the genus-specific bifidobacterial SSU rRNA-targeted oligonucleotide probe showed a treatment effect, this methodology does not reflect the activity of individual species encompassed by that probe. It is likely that individual species respond in different ways to different carbon sources, depending upon their ability to utilise the substrates added to the cultures. It has recently been demonstrated that substrate utilisation is highly variable among members of the genus Bifidobacterium and that there are considerable inter-species and inter-strain differences [14]. FOS and GOS were chosen for this experiment because they have been demonstrated to support the best growth of bifidobacteria in pure culture. In many species, maximum specific growth rates and bacterial cell yields were higher with oligosaccharides compared with their monosaccharide constituents [14]. Plate counts for the individual species in this experiment supported the concept of species-specific responses to different NDO. While there were minor variations in total bifidobacterial counts, sizeable differences were observed for $B$. adolescentis and B. angulatum.
The abundance of $E$. coli determined directly by plate counts and, along with other enterobacteria, by SSU rRNA-targeted oligonucleotide probe, indicated that both NDO restricted growth of this species. The unsupplemented control also consistently contained the greatest $E$. coli plate count or the greater abundance with the enterobacterial group probe. Although selective stimulation of bifidobacteria was observed with NDO in this experiment, this cannot be directly correlated to the reduction in E. coli. However, other workers who used pure cultures of bacteria demonstrated specific inhibition of $E$. coli by bifidobacteria $[6,8,35]$, which supports this contention.

While the present study has focused mainly on bifidobacteria, it has also been demonstrated that other bacteria commonly found in the large intestine are able to utilise NDO, particularly lactobacilli $[11,36]$. The production of antimicrobial peptides by lactobacilli is well documented [37] and may play a role in the observed reduction in abundance of enterobacterial SSU rRNA and culturable E. coli.

In conclusion, the two NDO investigated here, which are used as prebiotics, were shown to stimulate overall abundance of bifidobacterial SSU rRNA. While culture counts failed to show a response in terms of total populations of bifidobacteria there was evidence of species-specific utilisation of the substrates. In contrast, the SSU rRNA-targeted oligonucleotide probes demonstrated an increase in rRNA abundance for bifidobacterial populations with both NDO, considerably more so than with fructose. Future studies need to investigate the physiological and ecological mechanisms underlying the link between increased bifidobacterial numbers and the concomitant reduction in $E$. coli populations. 


\section{References}

1. Finegold SM, Sutter VL, Mathison GE. Normal indigenous intestinal flora. In: Hentges DJ (ed) Human intestinal microflora in health and disease. New York, Academic Press. 1983: 3.

2. Degnan BA. Transport and metabolism of carbohydrate by anaerobic gut bacteria. $\mathrm{PhD}$ thesis, Cambridge University, Cambridge. 1993.

3. Macfarlane GT, Gibson GR. Metabolic activities of the norma colonic microflora. In: Gibson SAW (ed) Human health: the contribution of microorganisms. London, Springer Verlag. 1994: $17-52$.

4. Mitsuoka T. Taxonomy and ecology of bifidobacteria. Bifid Microbiol 1984; 3: 11-28.

5. Macfarlane GT, Cummings JH. Probiotics and prebiotics: can regulating the activities of intestinal bacteria benefit health? BMJ 1999; 318: 999-1003.

6. Fujiwara S, Hashiba H, Hirota T, Forstner JF. Proteinaceous factor(s) in culture supernatant fluids of bifidobacteria which prevents the binding of enterotoxigenic Escherichia coli to gangliotetraosylceramide. Appl Environ Microbiol 1997; 63: 506-512.

7. Kimura K, McCartney AL, McConnell MA, Tannock GW. Analysis of fecal populations of bifidobacteria and lactobacilli and investigation of the immunological responses of their human hosts to the predominant strains. Appl Environ Microbiol 1997; 63: 3394-3398.

8. Gibson GR, Wang X. Regulatory effects of bifidobacteria on the growth of other colonic bacteria. J Appl Bacteriol 1994; 77: $412-420$.

9. O'Riordan K, Fitzgerald GF. Evaluation of bifidobacteria for the production of antimicrobial compounds and assessment of performance in cottage cheese at refrigeration temperature. $J$ Appl Microbiol 1998; 85: 103-114.

10. McBain AJ, Macfarlane GT. Ecological and physiological studies on large intestinal bacteria in relation to production of hydrolytic and reductive enzymes involved in formation of genotoxic metabolites. J Med Microbiol 1998; 47: 407-416.

11. Sghir A, Chow JM, Mackie RI. Continuous culture selection of bifidobacteria and lactobacilli from human faecal samples using fructooligosaccharide as selective substrate. $J \mathrm{Appl}$ Microbiol 1998; 85: 769-777.

12. Gibson GR, Beatty ER, Wang X, Cummings JH. Selective stimulation of bifidobacteria in the human colon by oligofructose and inulin. Gastroenterology 1995; 108: 975-982.

13. Rumney C, Rowland I. Non-digestible oligosaccharides potential anti-cancer agents? Br Nutr Bull 1995; 75: 194-203.

14. Hopkins MJ, Cummings $\mathrm{JH}$, Macfarlane GT. Inter-species differences in maximum specific growth rates and cell yields of bifidobacteria cultured on oligosaccharides and other simple carbohydrate sources. J Appl Microbiol 1998; 85: 381-386.

15. Stahl DA, Flesher B, Mansfield HR, Montgomery L. Use of phylogenetically based hybridization probes for studies of ruminal microbial ecology. Appl Environ Microbiol 1988; 54: 1079-1084.

16. Raskin L, Stromley JM, Rittman BE, Stahl DA. Group-specific 16S rRNA hybridization probes to describe natural communities of methanogens. Appl Environ Microbiol 1994; 60: 1232-1240.

17. Sharp R, Zeimer CJ, Stern MD, Cotta MA, Stahl DA. Taxonspecific associations between protozoal and methanogen populations in the rumen and a model rumen system. FEMS Microbiol Ecol 1998; 26: 71-78.

18. Doré J, Sghir A, Hannequart-Gramet G, Corthier G, Pochart P Design and evaluation of a 16S rRNA-targeted oligonucleotide probe for specific detection and quantitation of human faecal
Bacteroides populations. Syst Appl Microbiol 1998; 21: 65-71.

19. Pochart P, Gramet G, Goderel I, Doré J. Molecular characterization of the human fecal flora using rRNA-targeted hybridization probes. Gastroenterology 1998; 114: A902.

20. Sghir A, Gramet G, Suau A, Rochet V, Pochart P, Doré J. Quantification of bacterial groups within human fecal flora by oligonucleotide probe hybridization. Appl Environ Microbiol 2000; 66: 2263-2266.

21. Balch WE, Fox GE, Magrum LJ, Woese CR, Wolfe RS Methanogens: reevaluation of a unique biological group. Microbiol Rev 1979; 43: 260-296.

22. Macfarlane GT, Englyst HN. Starch utilization by the human large intestinal microflora. J Appl Bacteriol 1986; 60: 195201.

23. Beerens $H$. An elective and selective isolation medium for Bifidobacterium spp. Lett Appl Microbiol 1990; 11: 155-157.

24. Rogosa M, Mitchell JA, Wiseman RF. A selective medium for the isolation and enumeration of oral and fecal lactobacilli. $J$ Bacteriol 1951; 62: 132-133.

25. Holdeman LV, Moore WEC, Cato EP. Anaerobe laboratory manual, 4th edn. Blacksburg, VA, Virginia Polytechnic Institute and State University. 1977.

26. Miller L, Berger T. Bacteria identification by gas chromatography of whole cell fatty acids. Hewlett-Packard application note. Hewlett-Packard, Avondale, PA, USA. 1989: 228-241.

27. Amman RI, Krumholz L, Stahl DA. Fluorescent-oligonucleotide probing of whole cells for determinative, phylogenetic, and environmental studies in microbiology. J Bacteriol 1990; 172: $762-770$.

28. Langendijk PS, Schut F, Jansen GJ et al. Quantitative fluorescence in situ hybridization of Bifidobacterium spp. with genus-specific 16S rRNA-targeted probes and its application to fecal samples. Appl Environ Microbiol 1995; 61: 3069-3075.

29. Alm EW, Oerther DE, Larsen N, Stahl DA, Raskin L. The oligonucleotide probe database. Appl Environ Microbiol 1996; 62: $3557-3559$.

30. Sambrook J, Fritsch EF, Manniatis T. Molecular cloning: a laboratory manual, 2nd edn. Cold Spring Harbor, NY, Cold Spring Harbor Laboratory Press. 1989.

31. Newton DF, Cummings JH, Macfarlane S, Macfarlane GT. Growth of a human intestinal Desulfovibrio desulfuricans in continuous cultures containing defined populations of saccharolytic and amino acid fermenting bacteria. J Appl Microbiol 1998; 85: 372-380.

32. Hopkins MJ, Macfarlane GT. Evaluation of $16 \mathrm{~S}$ rRNA and cellular fatty acid profiles as markers of human intestinal bacterial growth using the chemostat. J Appl Microbiol 2000 (in press).

33. Sharp R, Ziemer CJ. Taxonomy, systematics and beyond: application of molecular techniques to intestinal microbiology. In: Gibson GR, Roberfroid MB (eds) Colonic microbiota, nutrition and health. Dordrecht, Kluwer Academic Publishers. 1999: $167-185$.

34. Welling GW, Elfferich P, Raangs GC, Wilderboer-Veloo ACM, Jansen GJ, Degener JE. 16S ribosomal RNA targeted oligonuceotide probes for monitoring of intestinal tract bacteria. Scand J Gastroenterol 1997; 32 Suppl 222: 17-19.

35. Faure JC, Schellenburg A, Bexter A, Wurzner HP. Barrier effect of Bifidobacterium longum on Escherichia coli in germfree rat. J Nutr Vit Res 1982; 52: 225-227.

36. May T, Mackie RI, Fahey GC, Cremin JC, Garleb KA. Effect of fiber source on short-chain fatty acid production and on the growth and toxin production by Clostridium difficile. Scand $J$ Gastroenterol 1994; 29: 916-922.

37. Barefoot SF, Klaenhammer TR. Detection and activity of Lactacin B, a bacteriocin produced by Lactobacillus acidophilus. Appl Environ Microbiol 1983; 45: 1808-1815. 